\title{
Surgical skills deficiencies and needs of rural general practitioners in South Africa
}

\author{
D C Porter, ${ }^{1}$ MB ChB, FCS (SA); J Bezuidenhout, ${ }^{1}$ DTechEd; R S du Toit, ${ }^{2}$ MB ChB, MMed, FCS (SA); A O Adefuye, ${ }^{1}$ MB ChB, MSc, PhD \\ ${ }^{1}$ Division Health Sciences Education, Office of the Dean, Faculty of Health Sciences, University of the Free State, Bloemfontein, South Africa \\ ${ }^{2}$ Department of Surgery, School of Medicine, Faculty of Health Sciences, University of the Free State, Bloemfontein, South Africa
}

Corresponding author: A O Adefuye (adefuyeao@ufs.ac.za)

\begin{abstract}
Background. At present, much of the global surgical workforce consists of non-specialist physicians (general practitioners (GPs)) whose only formal surgical training was in medical school as an undergraduate. However, there is widespread concern that GPs do not have the skills necessary to deliver essential surgical care in a rural setting. This requires that a specific training programme be developed to train rural GPs in essential surgical skills for rural settings.

Objectives. To perform a critical analysis to determine essential surgical skills required by GPs in rural South Africa, with the intention of developing the content of an accredited continuing professional development (CPD) learning programme to address needs identified. Methods. This was a descriptive study in which a desk-top review analysis and a questionnaire survey were used to obtain both qualitative and quantitative data on essential skills required for rural surgical practice.

Results. Of 300 GPs, 102 (34.0\%) completed the questionnaire. Some of the skills listed as essential for rural surgical practice were removal of foreign objects not in the visual axis $(90.0 \%)$, packing of epistaxis $(93.0 \%)$, haematoma drainage (78.3\%) and wound debridement and suturing $(96.0 \%)$. The study also identified the outcomes and essential content of a proposed CPD programme to provide GPs in the rural setting with the required surgical skills.

Conclusions. Enhancing skills of GPs in essential surgical techniques and procedures through an accredited CPD short learning programme will ensure that adequate and comprehensive essential surgical care is provided to people living in rural communities.
\end{abstract}

S Afr Med J 2018;108(3):210-216. DOI:10.7196/SAMJ.2018.v108i3.12611

Disease conditions treatable mainly by surgery constitute a substantial portion (30\%) of the global burden of disease. ${ }^{[1,2]}$ Although surgery is considered an essential component of health systems, it has been a neglected part of global health initiatives and has not been accorded the same priority as other preventive procedures in primary healthcare. ${ }^{[3]}$ It has been reported that about two billion people, particularly those living below the poverty line in low- and middle-income countries, many of whom reside in rural areas, do not have access to essential surgical care. ${ }^{[4]}$ One of the major barriers to surgical care in rural communities is an inadequate surgical workforce. ${ }^{[5]}$ This shortage has in part been attributed to inadequate salaries and poor working conditions, retirement of a capable surgical workforce in rural areas, ${ }^{[6]}$ difficulty in recruiting doctors to rural areas, ${ }^{[7,8]}$ and the brain drain of health staff to resource-rich countries. ${ }^{[9,10]}$ However, many countries have adopted and piloted a number of approaches to overcome this skills shortage. In the absence of trained surgeons, non-specialist physicians (general practitioners (GPs)) and in some cases non-physician clinicians (NPCs) are tasked with the responsibility of providing essential surgical care. ${ }^{[5]}$

In South Africa (SA), the role of and the range of skills required by a GP, as well as the spectrum of conditions that have to be managed in rural community hospitals, is both extremely wide and poorly documented. ${ }^{[11]}$ In the absence of specialist surgeons, the rural GP is tasked with the responsibility of performing clinical duties ranging from primary care to elective and emergency surgery. ${ }^{[12]}$ Jaques et al. ${ }^{[12]}$ reported that general surgical procedures are the major component of surgical procedures performed in rural hospitals in SA. The widespread concern that GPs do not have the surgical skills needed to deliver professional service in a rural setting ${ }^{[13]}$ and the fact that surgical procedures encountered during undergraduate medical training are very different from the day-to-day needs of general medical practice in rural areas ${ }^{[12]}$ mean that a specific training programme needs to be developed to train rural SA GPs in essential skills for specific surgical procedures.

The continuing professional development (CPD) programme implemented by the Health Professions Council of South Africa (HPCSA) is aimed at helping healthcare professionals maintain and acquire new and updated knowledge, skills and ethical attitudes for the benefit of the patient or client. ${ }^{[14]}$ To maintain their registration with the HPCSA, healthcare practitioners are required to accumulate a specific number of continuing education units each year. ${ }^{[14]}$

\section{Objectives}

To determine which specific surgical procedures GPs in rural SA need to be able to perform, and the contents of a CPD programme that could be developed to address these needs.

\section{Methods}

This research was designed as a descriptive study that made use of desktop review analysis (literature study) and a questionnaire survey to obtain both qualitative and quantitative data.

\section{Desktop/literature study}

A comprehensive literature search using the following key words: 'contents of a CPD programme in addressing essential surgical skills in SA rural areas for GPs', 'current level of surgical skills of GPs in rural areas', and 'essential surgical skills set needed by GPs in rural areas' was done using search engines such as EBSCO host, PubMed, medical student.com, Medscape, Google Scholar and Google Web. The explored literature provided a conceptual and contextual frame- 
work for the research and explored the following aspects: Surgical procedures performed in rural hospitals in Africa; and Framework for CPD programmes. In addition, documents pertaining to HPCSA CPD guidelines, the Council for Higher Education and the South African Qualifications Authority were analysed.

\section{Questionnaire survey}

The structured questionnaire used in this study was self-administered and was distributed electronically to participants using the EvaSys software program, version 7.1 (Electric Paper Evaluationssysteme $\mathrm{GmbH}$, Germany). The questionnaire comprised four main sections, and data collected were as follows:

- Section A. Biographical data: gender, age, qualifications, level of experience and postgraduate training.

- Section B. This section comprised questions relating to the GPs' current surgical practices in the past 12 months.

- Section C. This section explored what participants considered to be essential surgical skills for practice in rural SA.

- Section D. Open-ended questions in this section allowed for further input regarding essential skills needed, but also aimed to identify other factors that might impact on surgical practice in rural areas. An adapted three-point Likert scale (essential or useful or non-essential) was used to determine the essential surgical skills the GPs needed in rural surgical practice.

The questions in the questionnaire were formulated from the combined data in the various existing training models explored through the literature and desktop study. The electronic questionnaire was distributed to a total of 300 GPs and the survey lasted for 9 months (28 June 2014 - 24 February 2015). To improve the response rate, reminders were sent to all the participants at intervals.

\section{Target population}

The target population included all GPs in SA, registered with the HPCSA, working in rural areas or in an area where their referral hospital was a rural hospital.

\section{Sample size}

The survey population consisted of individuals who were willing to sign the consent forms and fill in the questionnaire. The sample consisted of 720 registered doctors representing all nine provinces, selected through a proportionate stratified random sampling design.

\section{Pilot study}

A pilot study was conducted to test the suitability of the study design and methods, the chosen data collection method and the overall structure of questionnaire. The participants were three GPs working in Uitenhage, Eastern Cape Province, SA. The findings of the pilot study confirmed the feasibility of the main study, as the participants did not recommend that changes be made to the structured questionnaire.

\section{Data collection and analysis}

The data collected from the structured questionnaire were analysed quantitatively using EvaSys software, and the results are presented as percentages in the form of tables and bar charts.

\section{Ethical considerations}

Approval for the research project was obtained from the Health Sciences Research Ethics Committee of the Faculty of Health Sciences, University of the Free State, and the Dean of the Faculty of Health Sciences, University of the Free State (ref. no. ECUFS
$186 / 2013)$. Permission to conduct the survey was also obtained from the Office of the Director-General of the National Department of Health.

\section{Results}

Despite several reminders and the researcher resending the questionnaires to the participants numerous times, only 102 of the initial 300 questionnaires distributed were returned, giving a response rate of $34.0 \%$.

\section{Demographic information on respondents to the questionnaire survey \\ Age of participants}

This question was answered by 98 of the 102 respondents. Ages ranged from 24 to 73 years, and of the respondents $22.4 \%$ were aged 20 - 29 years, $17.3 \% 30$ - 39 years, $23.5 \% 40$ - 49 years, $23.5 \% 50-59$ years, and $13.3 \%>59$ years.

\section{Gender of participants}

Three of the 102 respondents did not indicate their gender. Of those who did, $72.7 \%$ were male and $27.3 \%$ female.

\section{Basic medical qualification}

One respondent did not indicate the institution where his/her basic medical qualification was obtained, and three responses were recorded as not applicable. Information for the remaining respondents is set out in Table 1 .

\section{Years during which the participants completed their basic medical qualification}

The majority of the respondents who completed this section (28.7\%) qualified between the years 1990 and 1999, 23.4\% between the years 1980 and 1989, 19.1\% between the years 2000 and 2009 and $19.1 \%$ later than 2009 (Fig. 1), indicating that $>50 \%$ of the respondents had between 15 and 35 years of experience.

\section{Postgraduate medical qualification}

Of the 98 respondents who completed this section, 54.1\% (53/98) indicated that they did not have a postgraduate qualification. Of the $45.9 \%$ (45/98) who did have a further qualification, 16 had a master's degree in family medicine, 2 a master's degree in sports medicine, 5 a diploma in anaesthetics, 6 a diploma in HIV medicine, 1 a diploma in dermatology, 1 a certificate in travel medicine, 2 a

Table 1. Institutions where the respondents obtained their basic medical qualification $(N=98)$

\begin{tabular}{ll}
\hline University & Respondents, $\boldsymbol{n}$ (\%) \\
\hline Stellenbosch University & $26(26.5)$ \\
University of the Free State & $15(15.3)$ \\
University of Natal & $13(13.3)$ \\
University of Cape Town & $12(12.3)$ \\
$\begin{array}{l}\text { Medical University of Southern Africa } \\
\text { (Sefako Makgatho Health Sciences }\end{array}$ & $9(9.2)$ \\
University) & \\
$\begin{array}{l}\text { University of the Witwatersrand } \\
\text { University of Pretoria }\end{array}$ & $6(6.1)$ \\
$\begin{array}{l}\text { University of Transkei (Walter Sisulu } \\
\text { University) }\end{array}$ & $6(6.1)$ \\
$\begin{array}{l}\text { Other* } \\
\text { *University of Ibadan (Nigeria), Cuban medical school, University of Zimbabwe, Cairo } \\
\text { University, Ghana and University of Dar es Salaam (Tanzania) }(n=1 \text { each), India, Madrid } \\
\text { (Spain) }(n=2 \text { each). }\end{array}$ & $1(1.0)$ \\
\end{tabular}


diploma in obstetrics, 3 a diploma in diabetes, 1 a diploma in mental health, 1 a diploma in public health, 2 a diploma in palliative care medicine, 1 a diploma in occupational health, and 1 a diploma in aviation medicine; 1 was a medical examiner of divers, 1 had a certificate in integrative medicine, and 2 had a BSc Medical Sciences (Honours) in reproductive biology. Furthermore, some respondents listed additional qualifications such as the Advanced Trauma Life Support $(n=2)$ and Advanced Cardiovascular Life Support $(n=1)$, and others listed postgraduate degrees outside the medical field such as a master's in business administration $(n=1)$, a diploma in strategic management and an honours degree in psychology $(n=1)$.

\section{Nature of employment}

In this section, respondents were asked to indicate their nature of employment. Options given were private practice, governmental (full time), governmental (part time), private hospital, unemployed or 'other'. Of the 102 responses received, the majority (61.4\%) indicated that the respondent worked in private practice; $27.7 \%$ worked as full-time government employees and $5.9 \%$ as part-time government employees, while 5.0\% indicated 'other'. All the respondents who indicated 'other' reported that they worked in private practice with a sessional (part-time government appointment) at a hospital, a clinic or both. None of the respondents were unemployed or in the employment of a private hospital.

\section{Community where workplace located}

The majority of the 95 respondents who completed this section $(55.8 \%)$ indicated that their workplace was located in a small town, $27.4 \%$ indicated that it was in a rural area, while $16.8 \%$ indicated city/ urban areas.

\section{Province where workplace located}

The majority of the 98 respondents who completed this section $(42.4 \%)$ practised in the Eastern Cape, $10.1 \%$ in the Free State and $9.1 \%$ in Gauteng. Other figures recorded were $8.1 \%$ for the Western Cape, KwaZulu-Natal and the Northern Cape, $6.1 \%$ for Limpopo and 4.0\% for Mpumalanga and Northern Province.

\section{Opinions of GPs regarding essential skills required for rural surgical practice}

In this section of the questionnaire, respondents were asked to indicate whether they considered the investigated surgical skill

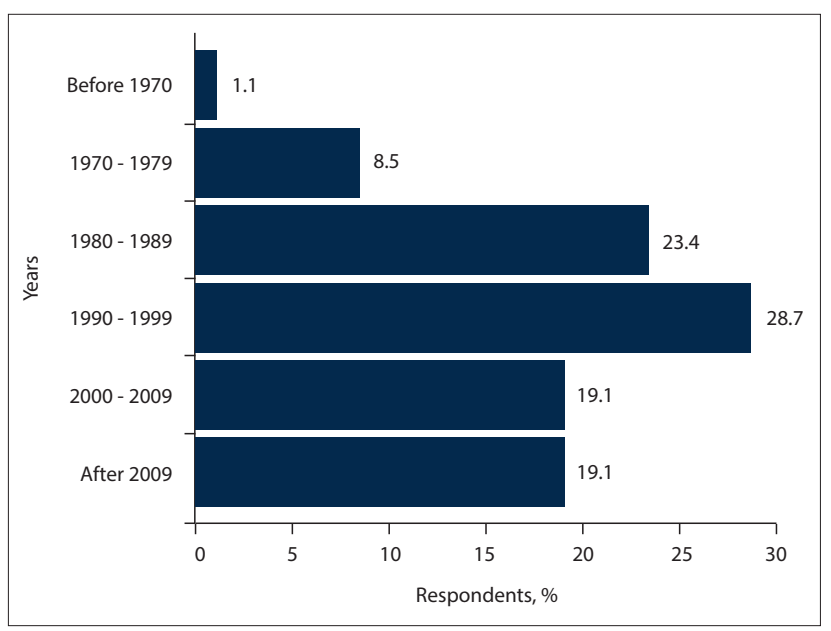

Fig. 1. Years during which the participants completed their basic medical studies $(\mathrm{N}=97)$. essential, useful or not needed in rural surgical practice. Results are grouped in different surgical fields and expressed in graphs.

\section{Ophthalmology procedures}

The respondents were asked to indicate whether uncomplicated cataract surgery, incision and drainage of a meibomian cyst and removal of a foreign object are essential, useful or not needed in rural surgical practice. The majority of the respondents (90.0\%) indicated that removal of a foreign object is an essential skill (Fig. 2).

\section{Ear, nose and throat procedures}

In the ear, nose and throat field, packing epistaxis and foreign body removal (uncomplicated) were considered essential for rural surgical practice by $93.0 \%$ and $89.2 \%$ of the respondents, respectively (Fig. 3).

\section{Abdominal procedures}

Asked which abdominal surgical procedures they considered to be essential, useful or not needed in rural surgical practice, $78.3 \%$ and $75.2 \%$ of the respondents indicated that ability to drain a perianal abscess and perform appendicectomy, respectively, are essential surgical skills (Fig. 4).

\section{Vascular procedures}

Performing vascular surgery for limb salvage is not feasible in rural settings, but uncomplicated amputations and vascular cut-downs

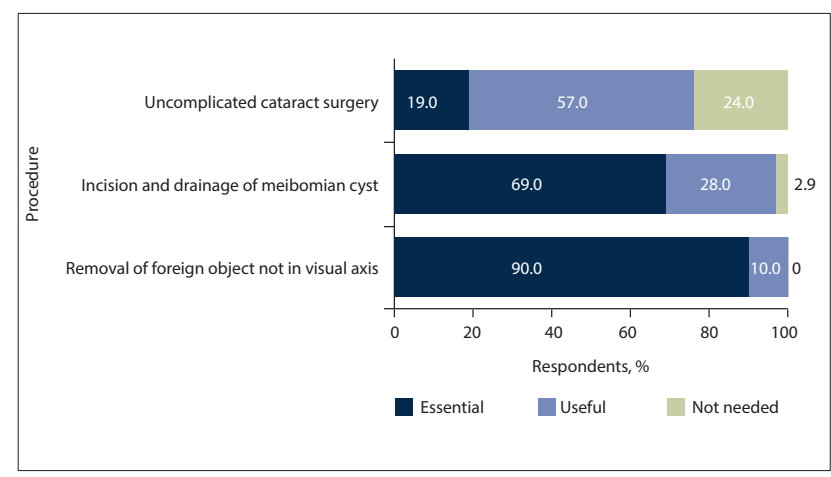

Fig. 2. Opinions of participants on ophthalmology procedures essential for rural surgical practice $(\mathrm{N}=101)$.

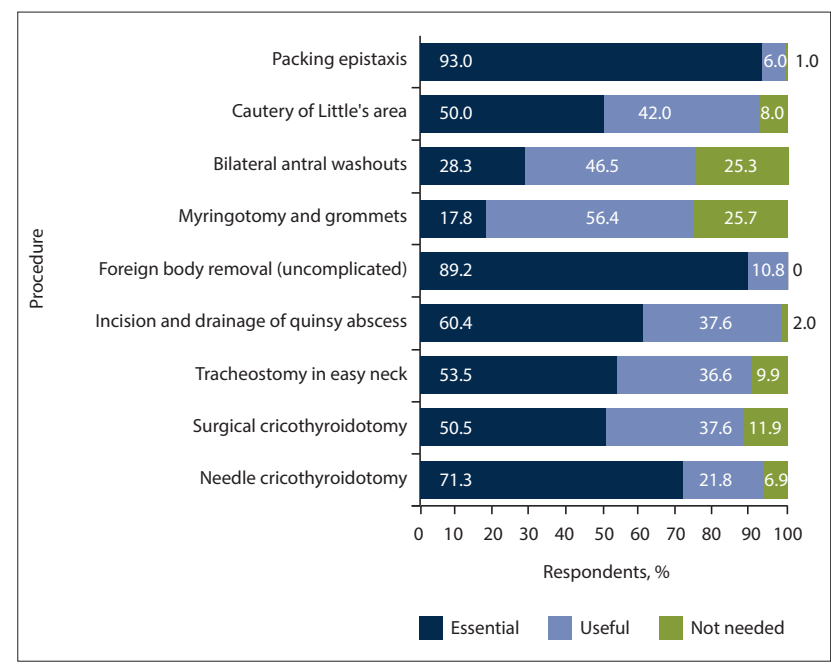

Fig. 3. Opinions of participants on ear, nose and throat procedures essential for rural surgical practice $(\mathrm{N}=101)$. 
are procedures that may be of value in rural surgical practice. Asked about these procedures, over half of the respondents indicated that skills regarding vascular cutdown procedures are essential, while only $43.9 \%$ were of the opinion that the ability to perform an uncomplicated amputation is an essential skill (Fig. 5).

\section{Skin and soft-tissue procedures}

Asked which skin and soft-tissue surgical procedures they considered essential, useful

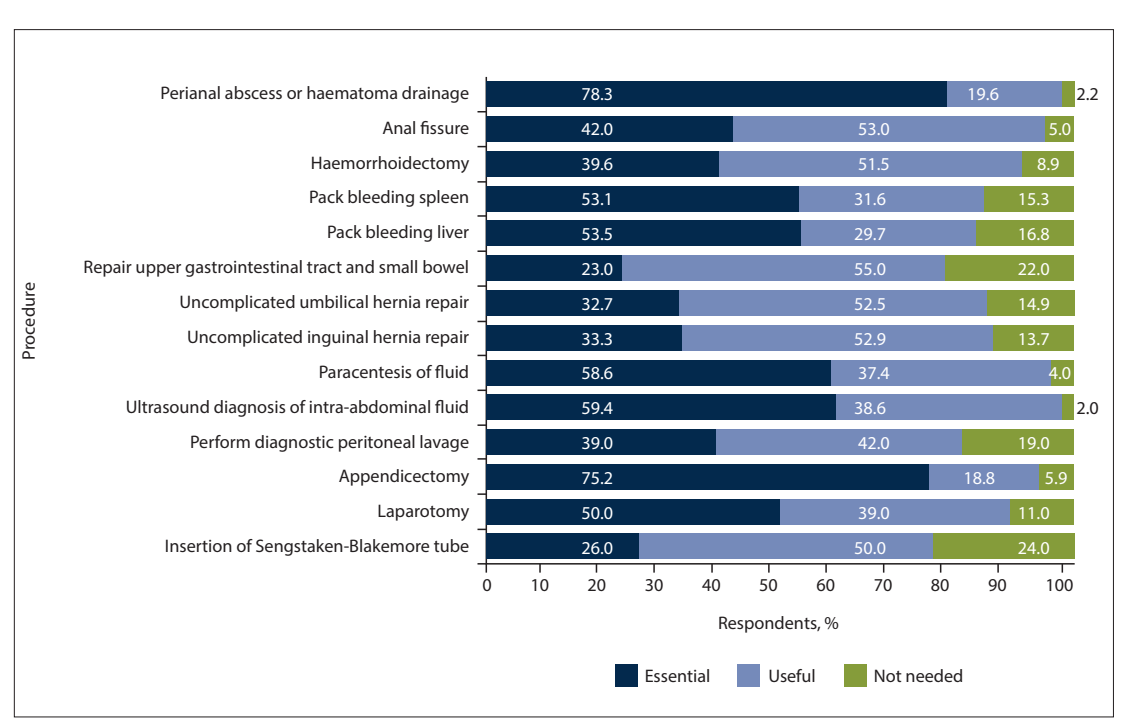

Fig. 4. Opinions of participants on abdominal procedures essential for rural surgical practice $(\mathrm{N}=101)$.

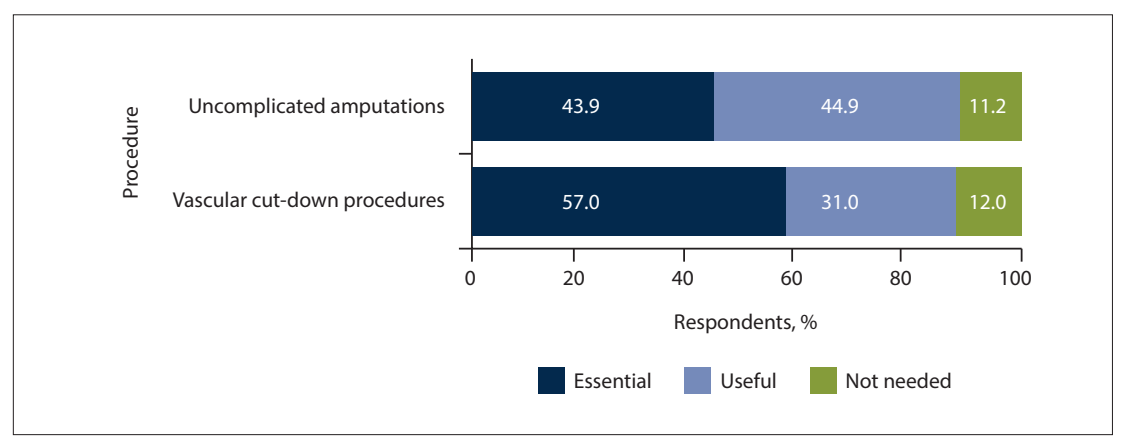

Fig. 5. Opinions of participants on vascular procedures essential for rural surgical practice $(\mathrm{N}=101)$.

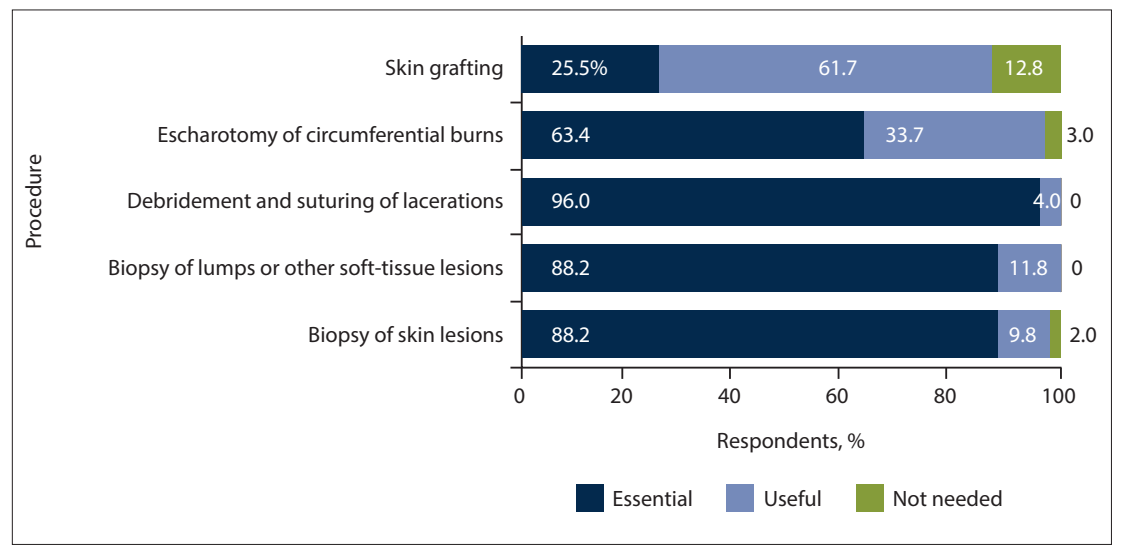

Fig. 6. Opinions of participants on skin and soft-tissue procedures essential for rural surgical practice $(\mathrm{N}=101)$. or not needed in rural surgical practice, the vast majority of the respondents $(96.0 \%)$ considered debridement and suturing of lacerations to be essential, and $88.2 \%$ that and biopsy of skin lesions are essential. Only $25.5 \%$ considered skin grafting essential for rural surgical practice (Fig. 6)

\section{Orthopaedic procedures}

With regard to orthopaedic surgical procedures, $74.3 \%$ of the respondents considered

\section{essential skills for rural surgical practice}

Table 2 sets out the contents that respondents thought should be included in a short learning programme in essential surgical skills for rural surgical practice. Consensus was deemed to have been achieved when at least $50 \%$ of the participants indicated that a procedure/skill is essential.

\section{Study outcomes of a CPD programme in essential skills for rural surgical practice}

In this open-ended question, participants were questioned on their opinions regarding specific outcomes that a CPD programme in essential skills for rural surgical practice should have. Responses to the open-ended questions are organised under two main (dominant) themes, together with some quotes based on the GPs' verbatim responses (with minor grammatical corrections without change of meaning) ( $N=68)$.

\section{Theme 1: Practical skills}

More than half of the respondents were of the opinion that a CPD programme in essential skills for rural surgical practice should enhance the development of good practical skills in rural surgery by providing hands-on training:

Quote 1: 'good practical skills'.

Quote 2: 'hands-on training.

Theme 2: Developing confidence in treating and operating on patients The second theme that emerged was increased confidence when making a surgical diagnosis and operating on patients. Here respondents felt that a CPD programme should help build confidence in these areas:

Quote 3: 'confidence in performing surgical operations'.

Quote 4: 'be capable of managing acute, life-threatening procedures confidently'.

Taken together, better skills and greater confidence would lead to a larger number of procedures being performed by GPs 


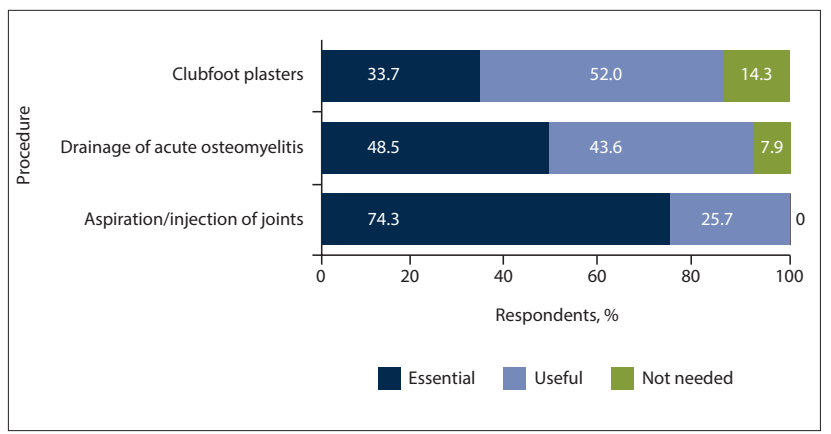

Fig. 7. Opinions of participants on orthopaedic procedures essential for rural surgical practice $(\mathrm{N}=101)$.

Table 2. Essential content for a CPD programme in essential skills for rural surgical practice

\begin{tabular}{ll} 
skills for rural surgical practice & \\
\hline & $\begin{array}{l}\text { Respondents } \\
\text { indicating the } \\
\text { skill essential, \% }\end{array}$ \\
Content & \\
\hline Ophthalmology procedures & 69.0 \\
Incision and drainage of meibomian cyst & 90.0 \\
Removal of foreign object not in visual axis & \\
Ear, nose and throat procedures & 93.0 \\
Packing epistaxis & 50.0 \\
Cautery of Little's area & 89.2 \\
Foreign body removal, uncomplicated & 60.4 \\
Incision and drainage of quinsy abscess & 53.5 \\
Tracheostomy in easy neck & 50.5 \\
Surgical cricothyroidotomy & 71.3 \\
Needle cricothyroidotomy & \\
Abdominal procedures & 78.3 \\
Perianal abscess or haematoma drainage & 53.1 \\
Pack bleeding spleen & 53.5 \\
Pack bleeding liver & 58.6 \\
Paracentesis of fluid & 59.4 \\
Ultrasound diagnosis of intra-abdominal fluid \\
Appendicectomy & 75.2 \\
Laparotomy & 50.0 \\
Vascular procedures & \\
Vascular cut-down procedures & 57.0 \\
Skin and soft-tissue procedures & \\
Escharotomy of circumferential burns & 63.4 \\
Debridement and suturing of lacerations & 96.0 \\
Biopsy of lumps and other soft-tissue lesions & 88.2 \\
Biopsy of skin lesions & 88.2 \\
Orthopaedic procedures & \\
Aspiration/injection of joints & 74.3 \\
Urological procedures & \\
Management of priapism & 78.4 \\
Testicular torsion (scrotal exploration) & 62.7 \\
Circumcision & 62.7 \\
Suprapubic catheterisation & \\
Urethral catheterisation & \\
CPD = continuing professional development. & \\
& \\
&
\end{tabular}

themselves to help reduce the mortality of surgically treatable diseases in rural communities, prevent unnecessary referrals and lower the patient burden in specialist healthcare facilities.

Participants suggested that such a CPD programme should be a short learning programme (SLP) (1 - 2 days), and affordable.

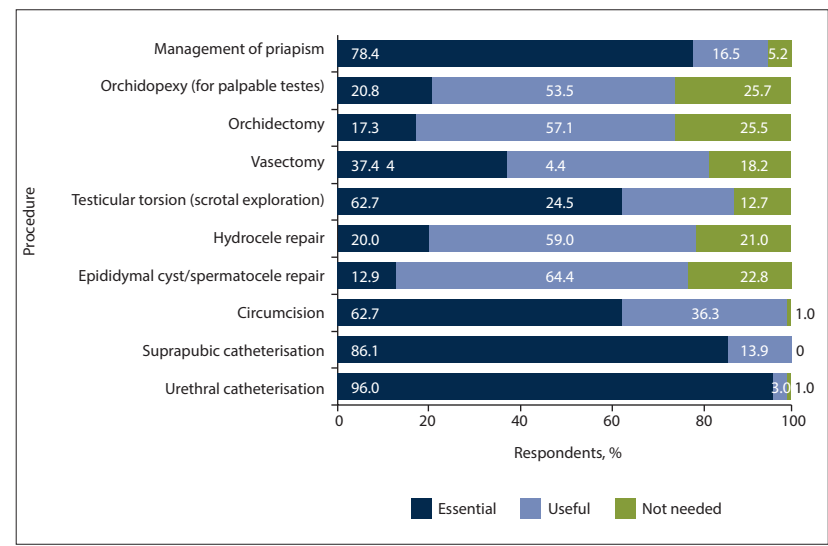

Fig. 8. Opinions of participants on urological procedures essential for rural surgical practice $(\mathrm{N}=101)$.

\section{Attending surgical skills courses}

In this final section of the questionnaire, participants were asked about their willingness to attend a surgical skills course and perform more procedures if trained in specific skills. Participants gave very positive responses when asked if they were willing to attend a surgical skills course: 99 respondents answered this question, and an overwhelming $92.0 \%$ indicated 'yes' in response. Similarly, 92.9\% of the respondents indicated that they would perform more procedures if trained in specific skills.

\section{Discussion}

It has been recognised that failure to appreciate the role of surgery in addressing important public health problems and confusion over what constitutes surgical care in settings of limited resources are the main causes of disparities in surgical care worldwide. ${ }^{[15]}$ Providing surgical services in rural areas remains a challenge globally. In a study aimed at investigating deaths from acute abdominal conditions and geographical access to surgical care in India, Dare et al. ${ }^{[16]}$ reported that $87 \%$ of deaths due to acute abdomen occurred in the rural areas. Similarly, Aboagye et al ${ }^{[17]}$ reported the existence of a rural-urban disparity in the density of general surgeons providing colorectal cancer screening services and treatment in the USA. In sub-Saharan Africa, providing rural surgical care has been plagued with numerous specific challenges such as inadequate remuneration and poor working conditions, difficulty in recruiting doctors to rural areas, ${ }^{[7,8]}$ and the brain drain of health staff to resource-rich countries. ${ }^{[9,10]}$

In order to meet the demands of providing rural surgical care, many countries have adopted and piloted a number of approaches. In the USA, active recruitment of general surgeons and changing surgical training programmes to draw surgeons to rural hospitals are ongoing. ${ }^{[18]}$ In Australia, the Royal Australasian College of Surgeons' Rural Surgical Training Program (RSTP), one of the first rural specialist training programmes in the world, ${ }^{[19]}$ ran from 1996 to 2007. The RSTP was essentially a general surgery training programme that supported recruitment and retention of rural surgeons by preparing trainees for rural practice. ${ }^{[20]}$ In Canada, a new curriculum has been proposed that will provide enhanced surgical skills to rural family physicians in an attempt to fortify a seamless network of high-quality surgical care for rural Canada. ${ }^{[21,22]}$ In subSaharan Africa, the concept of 'task shifting in surgery' (delegation of certain surgical responsibilities to NPCs) is being brought into practice, with reports of low morbidity and mortality rates. ${ }^{[5,23-25]}$

In $\mathrm{SA}$, as in the rest of the world, providing adequate and highquality surgical care in rural areas is a challenge faced by the present healthcare system. Traditionally, in the absence of specialist surgeons, 
the rural GP is tasked with the responsibility of providing primary surgical care. ${ }^{[12]}$ However, concerns that SA GPs do not have the essential surgical skills required to deliver professional service in a rural setting, ${ }^{[13]}$ and the fact that surgical procedures encountered during undergraduate medical training differ tremendously from day-to-day needs in rural areas, ${ }^{[12]}$ mean that a specific training programme needs to be developed to train rural GPs in essential skills for specific surgical procedures. In this study, the opinions of GPs on essential surgical skills required in rural SA were canvassed and the contents of a proposed CPD programme that would address these needs was developed.

Analysis of the study data reveals that of the ophthalmology procedures, removal of a superficial foreign body not in the visual axis and incision and drainage of a meibomian cyst were deemed essential by $90.0 \%$ and $69.0 \%$ of the respondents, respectively (Table 2). Similarly, packing epistaxis, cautery of Little's area, foreign body removal (ear and nose), uncomplicated incision and drainage of a quinsy abscess, tracheostomy in an easy neck, surgical cricothyroidotomy and needle cricothyroidotomy were considered essential skills for rural surgical practice by $>50 \%$ of the respondents. Appendicectomy and perianal abscess or haematoma drainage, which are common procedures performed in the rural setting, ${ }^{[26]}$ were ranked highest (75.2\% and $78.3 \%$, respectively) among the essential content for abdominal procedures that should be included in the CPD programme for rural surgical practice (Table 2). There was a general trend away from elective non-emergency procedures such as uncomplicated umbilical and uncomplicated inguinal hernia repairs, anal fissure and haemorrhoidectomy (Fig. 4).

Vascular cut-down procedures, an essential skill for emergency physicians, ${ }^{[27]}$ were considered essential by $57.0 \%$ of the respondents in this study (Table 2). Vascular cut-down procedures are of great importance as they facilitate fluid replacement in trauma patients in hypovolaemic shock with peripheral venous collapse. ${ }^{[27]}$ Of all the skin and soft-tissue procedures investigated in this study, debridement and suturing of lacerations was considered essential by the overwhelming majority (96.0\%) of the respondents. According to Lutge et al., ${ }^{[28]}$ there is a significant burden of injury/trauma in SA, so it is of the utmost importance that a GP working in a rural community is well skilled in wound management. Other skin and soft-tissue procedures considered essential for a CPD programme in essential skills for rural surgical practice include escharotomy of circumferential burns, biopsy of lumps and other soft-tissue lesions, and biopsy of skin lesions (Table 2). Respondents indicated that aspiration and injection of joints is an essential orthopaedic surgical skill. With regard to urological procedures, respondents indicated that management of priapism, testicular torsion (scrotal exploration), circumcision, suprapubic catheterisation and urethral catheterisation are all essential skills that a GP working in a rural hospital or clinic needs to have.

By obtaining the opinions of GPs, this study has developed a comprehensive list of essential contents that will be used to develop a CPD programme in skills necessary for rural surgical practice. The proposed programme can be standardised and presented as an SLP at any institution that has an adequately equipped clinical skills centre for the necessary simulation-based training. The programme outcomes and content described by this research can be applicable globally, wherever task shifting in surgery is necessary for providing adequate and comprehensive essential surgical care for people living in rural communities.

\section{Study strengths and limitations}

The major strength of this study is the obtaining of direct input from the people actively involved in the field, i.e. the GPs themselves. The
GPs obtained their qualifications from different institutions and practised in different settings. Their surgical skills needs and the expected outcomes of a CPD programme in essential skills for rural surgical practice were identified. The lower than expected response rate was the main observable setback encountered in this study. Despite numerous reminders sent to all the potential participants at intervals, only a third of the distributed questionnaires were received back. This low response rate was attributed to substantial after-hours duties and an excessive workload faced by GPs in rural hospitals. ${ }^{[29]}$

\section{Conclusion}

GPs are a vital workforce in rural communities. Enhancing their skills in essential surgical techniques or procedures through an accredited CPD short learning programme will ensure that adequate and comprehensive essential surgical care is provided to people living in rural communities, and further reduce the mortality of surgically treatable diseases in these communities.

Acknowledgements. We gratefully acknowledge the assistance received from the participating GPs, and the medical school administrators involved in collation of the data.

Author contributions. DCP designed the study, wrote the protocol, collected data, and performed analysis. AOA and JB performed data analysis and interpretation of data and wrote the manuscript. JB and RSduT reviewed the protocol and manuscript. All authors approved the final version of the manuscript submitted

Funding. This study was funded by a research grant from the Health and Welfare Sector Education Training Authority of South Africa.

Conflicts of interest. None.

Mock CN, Donkor P, Gawande A, Jamison DT, Kruk ME, Debas HT. Essential surgery: Key messages from Disease Control Priorities. Lancet 2015;385(9983):2209-2219. https://doi.org/10.1016/S01406736(15)60091-5

2. Shrime MG, Bickler SW, Alkire BC, Mock C. Global burden of surgical disease: An estimation from the provider perspective. Lancet Glob Health 2015;3:S8-S9. https://doi.org/10.1016/S2214$109 \mathrm{X}(14) 70384-5$

3. Stewart B, Khanduri P, McCord C, et al. Global disease burden of conditions requiring emergency surgery. Br J Surg 2014;101(1):e9-e22. https://doi.org/10.1002/bjs.9329

4. Funk LM, Weiser TG, Berry WR, et al. Global operating theatre distribution and pulse oximetry supply: An estimation from reported data. Lancet 2010;376(9746):1055-1061. https://doi.org/10.1016/ S0140-6736(10)60392-3

Chu K, Rosseel P, Gielis P, Ford N. Surgical task shifting in sub-Saharan Africa. PLoS Med 2009;6(5):e1000078. https://doi.org/10.1371/journal.pmed.1000078

6. Hindle H. For want of a scalpel. Can I Rural Med 2006:11(3):185-187.

7. Viscomi M, Larkins S, Gupta T. Recruitment and retention of general practitioners in rural Canada and
7. Australia: A review of the literature. Can J Rural Med 2013;18(1):13.

8. Wasko K, Jenkins J, Meili R. Medical practice in rural Saskatchewan: Factors in physician recruitment Wasko K, Jenkins J, Meili R. Medical practice in r
and retention. Can J Rural Med 2014;19(3):93-98.

and retention. Can J Rural Med 2014;19(3):93-98.
9. Ihekweazu C, Anya I, Anosike E. Nigerian medical graduates: Where are they now? Lancet 9. Thekweazu C, Anya I, Anosike E. Nigerian medical graduates: Where
2005;365(9474):1847-1848. https:// $\mathrm{doi} .0 \mathrm{org} / 10.1016 / \mathrm{S} 0140-6736(05) 66612-3$

10. Mullan F. The metrics of the physician brain drain. N Engl J Med 2005;353(17):1810-1818. https://doi. org/10.1056/NEJMsa050004

11. De Villiers M, van Velden D. Curriculum development for the rural specialist. S Afr Med J 1996;86(12):1528-1528.

12. Jaques P, Reid S, Chabikuli O, Fehrsen S. Developing Appropriate Skills for Rural Doctors. Phase I; Procedural Skills of Rural Doctors in South Africa. Durban: Health Systems Trust, 1999.

13. Halaas GW, Zink T, Finstad D, Bolin K, Center B. Recruitment and retention of rural physicians: Outcomes from the rural physician associate program of Minnesota. J Rural Health 2008;24(4):345352. https://doi.org/10.1111/j.1748-0361.2008.00180.x

14. Health Professions Council of South Africa (HPCSA). CPD. http://www.hpcsa.co.za/CPD (accessed 8 May 2017)

15. Bickler SW, Weiser TG, Kassebaum N, et al. Global burden of surgical conditions. In: Debas HT, . Bickler SW, Weiser TG, Kassebaum N, et al. Global burden of surgical conditions. In: Debas HT, Donkor P, Gawande A, Jamison DT, Kruk ME, Mock CN, eds. Essential Surgery:
Priorities, vol. 1. 3rd ed. 2015. Washington, DC: World Bank Publications, 2015.

Priorities, vol. 1. 3rd ed. 2015. Washington, DC: World Bank Publications, 2015.
6. Dare AJ, Ng-Kamstra JS, Patra J, et al. Deaths from acute abdominal conditions and geographical access to surgical care in India: A nationally representative spatial analysis. Lancet Glob Health 2015;3(10):e646-e653. https://doi.org/10.1016/S2214-109X(15)00079-0

17. Aboagye JK, Kaiser HE, Hayanga AJ. Rural-urban differences in access to specialist providers of colorectal cancer care in the United States: A physician workforce issue. JAMA Surg 2014;149(6):537543. https://doi.org/10.1001/jamasurg.2013.5062

18. Zastrow AW. Dilemma of general surgery recruitment in rural America. World J Surg 2006;30(3):269270. https://doi.org/10.1007/s00268-005-0564-1

19. Campbell G. Rural surgical training in Australia. Aust N Z J Surg 2007;77(11):922-923. https://doi, org/10.1111/j.1445-2197.2007.04282.x

20. Chong A, Kiroff G. Preparing surgeons for rural Australia: The RACS Rural Surgical Training Program. Aust N Z J Surg 2015;85(3):108-112. https://doi.org/10.1111/ans.12880

21. Caron N, Iglesias S, Friesen R, et al. A proposal for the curriculum and evaluation for training rural family physicians in enhanced surgical skills. Can J Surg 2015;58(6):419-422. https://doi.org/10.1503/
forat cjs.002215 
22. Warnock G, Miles P. Why Canada needs networks to provide rural surgical care, including family doctors with essential surgical skills. Can J Surg 2015;58(6):367-368. https://doi.org/10.1503/ doctors with 014715
cjs

23. Ozgediz D, Galukande M, Mabweijano J, et al. The neglect of the global surgical workforce: Experience and evidence from Uganda. World J Surg 2008;32(6):1208-1215. https://doi.org/10.1007/s00268-008-9473-4 4. Pereira C, Cumbi A, Malalane R, et al. Meeting the need for emergency obstetric care in Mozambique Work performance and histories of medical doctors and assistant medical officers trained for surgery. Work performance and histories of medical doctors and assistant medical officers
BJOG 2007;114(12):1530-1533. https://doi.org/10.1111/j.1471-0528.2007.01489.x

25. Chilopora G, Pereira C, Kamwendo F, Chimbiri A, Malunga E, Bergström S. Postoperative outcome of caesarean sections and other major emergency obstetric surgery by clinical officers and medical officers in Malawi. Hum Resour Health 2007;5(1):17. https://doi.org/10.1186/1478-4491-5-17

26. Borgstrom DC, Lopez M, Hoesterey D, Victory J, Urayeneza O. Management of acute appendicitis in a rural population. Am J Surg 2016;212(3):451-454. https://doi.org/10.1016/j.amjsurg.2015.10.020
27. Knopp R. Venous cutdowns in the emergency department. J Am Coll Emerg Physicians 1978;7(12):439443. https://doi.org/10.1016/S0361-1124(78)80129-4

28. Lutge E, Moodley N, Tefera A, Sartorius B, Hardcastle T, Clarke D. A hospital based surveillance system to assess the burden of trauma in KwaZulu-Natal Province South Africa. Injury 2016;47(1):135140. https://doi.org/10.1016/j.injury.2015.08.020

29. De Villiers M, de Villiers P. Doctors' views of working conditions in rural hospitals in the Western Cape. S Afr Fam Pract 2004;46(3):21-26. https://doi.org/10.1080/20786204.2004.10873056

Accepted 24 August 2017 